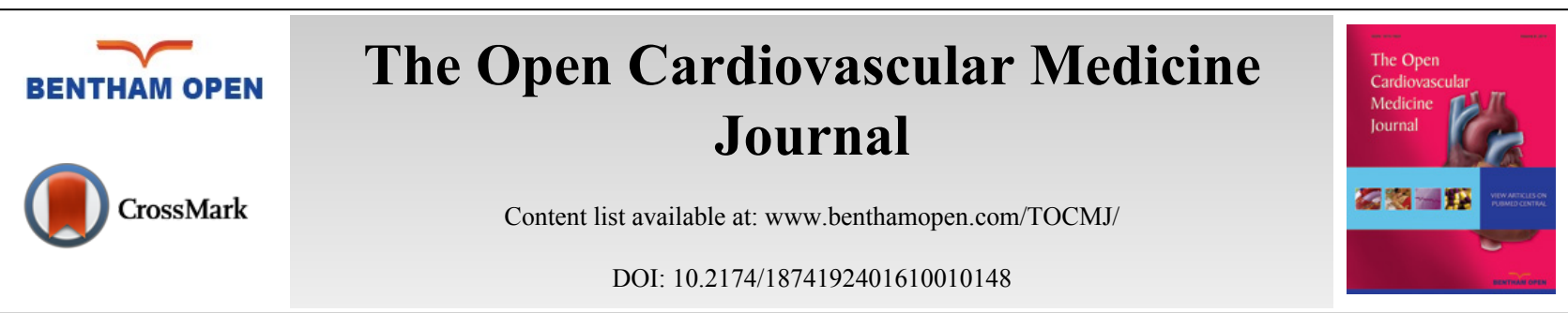

RESEARCH ARTICLE

\title{
Allogeneic Blood Product Usage in Coronary Artery Bypass Grafting (CABG) with minimalized Extracorporeal Circulation System (MECC) Versus Standard On-Pump Coronary Artery Bypass Grafting
}

\author{
M. Lisy ${ }^{1, *}$, E. Schmid ${ }^{2}$, J. Kozok ${ }^{3}$, P. Rosenberger ${ }^{2}$, U.A. Stock ${ }^{4}$ and G. Kalender ${ }^{1}$ \\ ${ }^{I}$ Department of General, Visceral, Thoracic and Vascular Surgery, Frankfurt-Höchst City Hospital, Höchst, Germany \\ ${ }^{2}$ Department of Anaesthesia and Intensive Care, University Hospital Tuebingen, Tuebingen, Germany \\ ${ }^{3}$ Department of Thoracic, Cardiac and Vascular Surgery, University Hospital Tuebingen, Tuebingen, Germany \\ ${ }^{4}$ Department of Thoracic and Cardiovascular Surgery, University Hospital Frankfurt am Main, Höchst, Germany
}

\section{Abstract:}

Aim:

Intraoperative allogeneic blood product transfusion (ABPT) in cardiac surgery is associated with worse overall outcome, including mortality. The objective of this study was to evaluate the ABPTs in minimalized extracorporeal cardiopulmonary $\left(\mathrm{MECC}^{\mathrm{TM}}\right)$ compared with standard open system on-pump coronary revascularization.

\section{Methods:}

Data of 156 patients undergoing myocardial revascularization between September 2008 and September 2010 were reviewed. 83 patients were operated by the MECC technique and 73 were treated by standard extracorporeal circulation (sECC). ABPT and overall early postoperative complications were analyzed.

Results:

Operative mortality and morbidity were similar in both groups. ABPT in the MECC group was significantly lower than in the sECC group both intraoperatively $(7.2 \mathrm{vs} .60 .3 \%$ of patients $\mathrm{p}<0.001)$ and during the first five postoperative days $(19.3 \mathrm{vs} .57 .5 \%$; $\mathrm{p}<0.001)$. "Skin to skin"- $(214 \pm 45$ vs. $232 \pm 45 \mathrm{~min} ; \mathrm{p}=0.012)$, cardiopulmonary bypass $(\mathrm{CPB})-(82 \pm 25$ vs. $95 \pm 26 \mathrm{~min}$; $\mathrm{p}=0.014)$, and X-clamp- times $(50 \pm 16 v s .56 \pm 17 \mathrm{~min} ; \mathrm{p}=0.024)$ were significantly lower in the MECC group than in the sECC group. Length of ICU (intensive care unit) - and hospital stay were also significantly lower in the MECC group $v s$. the sECC group $(26.7 \pm 20.2$ vs. $54.5 \pm 68.9 \mathrm{~h} ; \mathrm{p}<0.001$, and $12.0 \pm 4.1$ vs. $14.5 \pm 4.6$ days; $\mathrm{p}<0.001)$.

\section{Conclusion:}

Application of MECC as on-pump coronary artery bypass graft (CABG) results in significantly lower ABPT as well as shorter ICU and in-hospital stay. In order to achieve these benefits of MECC autologous retrograde priming, Bispectral index (BIS) monitoring, intraoperative cell salvage, meticulous hemostasis and strict peri- and postoperative volume management are crucial.

Keywords: Blood transfusion, Coronary artery bypass graft, Cardiopulmonary bypass, Extracorporeal circulation.

\footnotetext{
* Address correspondence to this author at the Department of General, Visceral, Thoracic and Vascular Surgery, Frankfurt-Höchst City Hospital, Gotenstrasse 6-8, 65929 Frankfurt am Main, Germany; Tel: (0049) 69-3106- 2871; Fax: (0049) 69-3106-2410; E-mail: lisy90@googlemail.com
} 


\section{INTRODUCTION}

Transfusion of red blood cells (RBCs) in patients undergoing coronary artery bypass graft (CABG) surgery is associated with increased mortality and morbidity. Large numbers of studies identified multiple adverse effects attributed to allogeneic RBCs such as overall increase of septic perioperative complications, systemic inflammatory reaction syndrome (SIRS) and transfusion-related acute lung injury (TRALI) [1].

Application of closed minimalized extracorporeal pump circuits $\left(\mathrm{MECC}^{\mathrm{TM}}\right)$ using normothermic conditions is reported to minimize priming volume, avoid air-blood contact, thereby avoiding excessive hemodilution, hemolysis and other associated more discrete hemostatic disturbances resulting in a diminished perioperative blood product administration [2, 3].

Anticipating that the MECC system may reduce allogeneic blood product requirement, we conducted a retrospective study to compare the incidence of transfusion in patients undergoing coronary revascularization by MECC vs. SECC.

\section{PATIENTS AND METHODS}

\section{Patients}

The Ethics Committee of the University of Tuebingen approved the study. According to the Ethics Committee, individual consent was not necessary because of the study's retrospective design.

We analyzed 156 patients operated between September 2008 and September 2010 at the Department of Thoracic and Cardiovascular Surgery at the University Hospital Tuebingen. Reoperations, operations other than isolated on-pump CABG performed through a full median sternotomy were excluded; 83 patients (53\%) underwent MECC and 73 (47\%) sECC.

\section{Outcome Parameters}

Primary outcome parameters compromised incidence and amount of intra and early postoperative ABPT, postoperative ventilation time, ICU (intensive care unit) stay, overall in hospital stay.

\section{MECC Procedure}

Operations were performed via median sternotomy. The internal mammary arteries (IMA) were prepared striving to leave both pleura intact, in order to prevent blood surge into the open pleural cavities during surgery. The left IMA was always used to graft the left anterior descending coronary artery (LAD) or a dominant diagonal branch. The right IMA was used as T-Graft to graft the circumflex and the diagonal branch. The right coronary artery was revascularized using the great saphenous vein. Closed and fully heparinized (150 IU/KG) minimalized extracorporeal pump circuit $\left(\mathrm{MECC}^{\mathrm{TM}}\right)$, aortic $(21-24 \mathrm{~F})$ and 3-stage venous cannulation (24-28F) was employed. The components of MECC included a membrane oxygenator (Quadrox D, Maquet), a centrifugal pump and a table line (3/8-180 cm). Autologous retrograde priming limited overall priming to $500 \mathrm{ml}$. Target activated clotting time (ACT) was 200 to $250 \mathrm{sec}$. Anesthesia was maintained by sevoflurane and high dose opiods with bispectral index (BIS) monitoring. Cardiac arrest was achieved with warm Calafiore blood cardioplegia (an average $5 \mathrm{ml}$ of crystalloid solution was added). Blood from the operation field as well as from MECC circuit following weaning from CPB was collected and processed in a cell saver (average $500 \mathrm{ml}$ ).

\section{sECC Procedure}

sECC circuit consisted of tube system without heparin coating, Quadrox D (Maquet) oxygenator, two stage venous cannula $(32-50 \mathrm{~F})$ and aortic cannula $(21-24 \mathrm{~F})$. The priming volume was $1500 \mathrm{ml}$. A non-pulsatile Roller pump (Maquet) established a blood flow of $2.4 \mathrm{~L} \cdot \mathrm{min}^{-1} . \mathrm{m}^{-2}$. The system required full systemic heparinization (300 IU/kg with target activated clotting time of above $400 \mathrm{sec}$ ). The cardiac arrest was achieved with Buckberg cold blood cardioplegia $(1500 \mathrm{ml})$. The core temperature was at $32^{\circ} \mathrm{C}$. Cell saving was not employed.

\section{Intraoperative Data}

Graft material, operation time, CPB time, X-clamp time, reperfusion, intra-aortic balloon pump. 


\section{Postoperative Monitoring}

Postoperative blood analysis compromised creatine kinase, hemoglobin, serum creatinine and lactate. Postoperative monitoring included intensive care unit (ICU) stay, ventilation time, transfusion of blood components, catecholamine dosage, drainage loss and for in-hospital course the parameters of symptomatic transitory psychotic syndrome, postoperative dialyses and overall in-hospital stay.

\section{Statistical Analysis}

Statistical analysis was performed using SPSS 19 software package for Windows (SPSS Inc., Chicago, Illinois, USA). Distribution of data was primarily assessed by visual analysis of histogram. The Kolmogorov-Smirnov test was used for equivocal scatters. Normally distributed data were analyzed either with the Student t-test for continuous or Pearson's chi- ${ }^{2}$ test for dichotomous variables. Fisher's exact test was used if the expected frequency on Chi- ${ }^{2}$ test was $<$ 5. In the case of non-normal distribution, the Mann-Whitney U test was used. A $p<0.05$ was considered significant.

Unless otherwise stated, results are expressed as mean \pm standard deviation.

\section{RESULTS}

Demographic data and comorbidities are summarized in Table 1, revealing no significant differences between the two groups.

Table 1. Demographic data.

\begin{tabular}{|c|c|c|c|}
\hline & & & MECC \\
\hline sECC & $\mathrm{p}$ & Number of patients & 83 \\
\hline 73 & & Mean age (years) & $66.3 \pm 9.5$ \\
\hline $69.0 \pm 8.9$ & 0.072 & Gender m/f, n (\%) & $66 / 17(79.5 / 20.5)$ \\
\hline $51 / 22(69.9 / 31.1)$ & 0.165 & BMI & $28.5 \pm 3.6$ \\
\hline $27.7 \pm 4.5$ & 0.218 & Ejection fraction, $\%$ & $53.6 \pm 15.9$ \\
\hline $55.6 \pm 12.2$ & 0.374 & CAD & $2.8 \pm 0.4$ \\
\hline $2.8 \pm 0, .4$ & 0,755 & Single-vessel CAD, n (\%) & $1(1.2)$ \\
\hline 0 & - & Two-vessel CAD, n (\%) & $14(16.9)$ \\
\hline $15(20.5)$ & - & Triple-vessel CAD, n (\%) & $68(81.9)$ \\
\hline $58(79.5)$ & - & Arterial hypertension, $\mathrm{n}(\%)$ & $76(91.6)$ \\
\hline $72(98.6)$ & 0.068 & Smoking, n (\%) & $41(49.4)$ \\
\hline $28(38.4)$ & 0.166 & Diabetes n (\%) & $33(39.8)$ \\
\hline $32(43.8)$ & 0.606 & COPD, n (\%) & $12(14.5)$ \\
\hline $7(9.6)$ & 0.354 & PAH, n (\%) & $5(6.0)$ \\
\hline $3(4.1)$ & 0.724 & Previous AMI ( $>30$ days), $\mathrm{n}(\%)$ & $31(37.3)$ \\
\hline \multirow[t]{2}{*}{$21(28.8)$} & 0.257 & Left main disease & \\
\hline & 0.679 & $<50 \%, \mathrm{n}(\%)$ & $36(43.4)$ \\
\hline $34(46.6)$ & - & $50-90 \%, \mathrm{n}(\%)$ & $30(36.1)$ \\
\hline $28(38.4)$ & - & $\geq 90 \%, \mathrm{n}(\%)$ & $17(20.5)$ \\
\hline $11(15.1)$ & - & Carotid artery stenosis, $\mathrm{n}(\%)$ & $14(16.9)$ \\
\hline $9(12.3)$ & 0.425 & EuroScore II, \% & $5.0 \pm 3.0$ \\
\hline
\end{tabular}

\section{Perioperative Data}

In MECC group, we observed a significantly shorter aortic X-clamp-time, CPB-time and operation time. Heparin and the antagonizing protamine doses were also significantly lower in the MECC group (Table 2).

Table 2. Intraoperative data.

\begin{tabular}{|c|c|c|c|}
\hline & MECC & sECC & p \\
\hline Operation time (min) & $214 \pm 45$ & $232 \pm 45$ & 0.012 \\
\hline CPB time (min) & $82 \pm 25$ & $95 \pm 26$ & 0.014 \\
\hline X-clamp-time (min) & $50 \pm 16$ & $56 \pm 17$ & 0.024 \\
\hline Reperfusion (min) & $27 \pm 13$ & $30 \pm 12$ & 0.004 \\
\hline
\end{tabular}


(Table 2) contd.....

\begin{tabular}{|c|c|c|c|}
\hline & MECC & sECC & $\mathbf{p}$ \\
\hline Cellsaver (ml) & $691 \pm 444$ & - & - \\
\hline Heparin (IU) & $14796 \pm 5164$ & $39638 \pm 12460$ & $<0.001$ \\
\hline Protamine (IU) & $14218 \pm 5107$ & $40191 \pm 10174$ & $<0.001$ \\
\hline LIMA, n (\%) & $80(96.4)$ & $68(93.2)$ & 0.475 \\
\hline A. radialis, $\mathrm{n}(\%)$ & $11(13.3)$ & $2(2.7)$ & 0.018 \\
\hline RIMA, n (\%) & $13(15.7)$ & $3(4.1)$ & 0.018 \\
\hline Saphenous Vein, n (\%) & $71(85.5)$ & $72(98.6)$ & 0.003 \\
\hline Number of distal anastomoses & $3.2 \pm 0.8$ & $3.6 \pm 0.8$ & 0.023 \\
\hline
\end{tabular}

CPB- cardiopulmonary bypass, LIMA- left internal mammary artery, RIMA - right internal mammary artery.

MECC - minimalized extracorporeal cardiopulmonary system

sECC - standard extracorporeal circulation

In Table 3 different time data characteristic for postoperative recovery are depicted, being significantly lower in the MECC group.

Table 3. Intensive data.

\begin{tabular}{|c|c|c|c|}
\hline & МECC & sECC & $\mathbf{p}$ \\
\hline Hospital stay (d) & $12.0 \pm 4.1$ & $14.5 \pm 4.6$ & $<0.001$ \\
\hline Intensive care unit (h) & $26.7 \pm 20.2$ & $54.5 \pm 68.9$ & $<0.001$ \\
\hline Intermediate care unit $(\mathrm{h})$ & $41.0 \pm 25.2$ & $57.3 \pm 46.4$ & 0.014 \\
\hline Duration of ventilation (h) & $14.1 \pm 6.9$ & $36.4 \pm 61.2$ & $<0.001$ \\
\hline 24-h drainage loss (ml) & $428 \pm 280$ & $656 \pm 341$ & $<0.001$ \\
\hline
\end{tabular}

MECC - minimalized extracorporeal cardiopulmonary system

sECC - standard extracorporeal circulation

\section{Transfusion Requirements}

Incidence of perioperative transfusion in sECC group was 8.3 times higher compared with the MECC group. This difference is even more striking if we consider, that the 6 transfused patients in the MECC group received only RBCs without any fresh-frozen plasma or platelets.

Considering the ABPT in the first 5 postoperative days the perioperative data were confirmed (Table 4).

Table 4. Required transfusion.

\begin{tabular}{|c|c|c|}
\hline & MECC & sECC \\
\hline periop. transfusion, n (\%) & $6(7,2)$ & $44(60)$ \\
\hline RBC (ml) & $375 \pm 141$ & $723 \pm 419$ \\
\hline FFP (ml) & - & $777 \pm 576$ \\
\hline Platelets (ml) & - & $403 \pm 150$ \\
\hline RBC (ml) & $16(19,3)$ & $42(57,5)$ \\
\hline FFP (ml) & $379 \pm 138$ & $655 \pm 548$ \\
\hline Platelets (ml) & $450 \pm 71$ & $<0,001$ \\
\hline
\end{tabular}

RBC - red blood cell, FFP - fresh frozen plasma.

MECC - minimalized extracorporeal cardiopulmonary system.

sECC - standard extracorporeal circulation

Although the administration of fresh frozen plasma during early perioperative period was less restrictive, amount in the MECC group was significantly lower. No platelet products were administered in the MECC group.

\section{Biochemical Results}

Preoperative hemoglobin levels in both groups were similar. Evolution pattern over the observed time of those values was similar in both groups. Values at the end of surgery (MECC: $11.2 \pm 1.1 \mathrm{vs}$. sECC $10.2 \pm 1.1 \mathrm{~g} / \mathrm{dl} ; \mathrm{p} \leq 0.001$ ) were significantly different as was the initial drop during the first $4 \mathrm{~h}$ (MECC: $11.4 \pm 1.4 \mathrm{vs}$. sECC $10.6 \pm 1.1 \mathrm{~g} / \mathrm{dl}$; 
$\mathrm{p} \leq 0.001)$. In both groups, the values decreased further $24 \mathrm{~h}$ and $72 \mathrm{~h}$ postoperatively and reached their minimum $72 \mathrm{~h}$ post-operatively (Fig. 1).

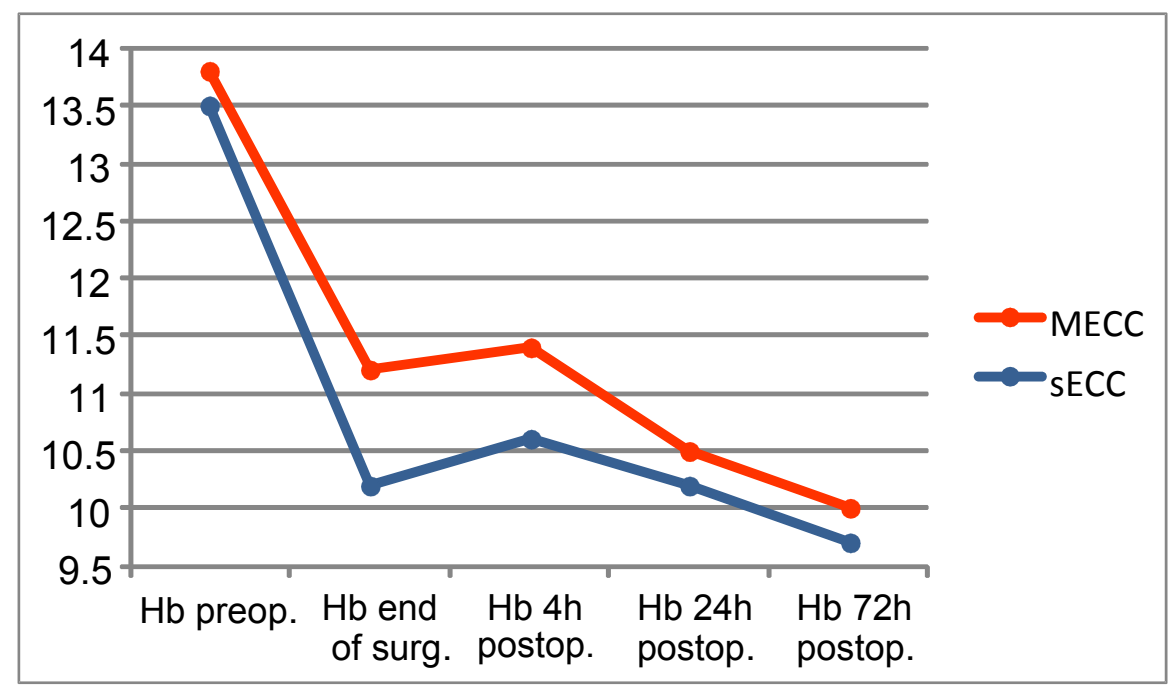

Fig. (1). Hemoglobin levels.

The hematocrit level revealed a similar course as hemoglobin level (Fig. 2).

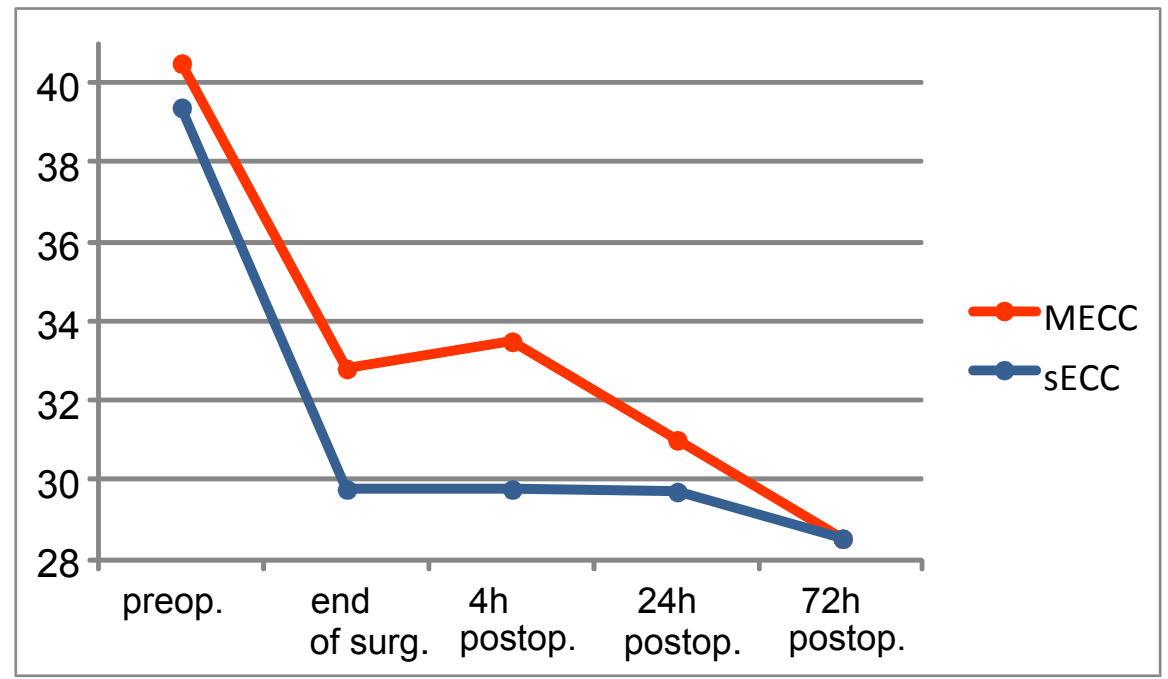

Fig. (2). The evolution of hematocrit levels during the first $72 \mathrm{~h}$.

Neither creatine kinase (CK) or creatine kinase myocardial band (CK-MB) values increased in both groups and remained up to $24 \mathrm{~h}$ postoperatively above the initial level achieving their peak at $24 \mathrm{~h}$ post-operatively. Up to $4 \mathrm{~h}$ postoperatively the MECC group showed a significantly smaller increase in CK values (MECC: $422 \pm 180$ vs. sECC: $550 \pm 227 \mathrm{U} / 1, \mathrm{p} \leq 0.001)($ Fig. 3) 


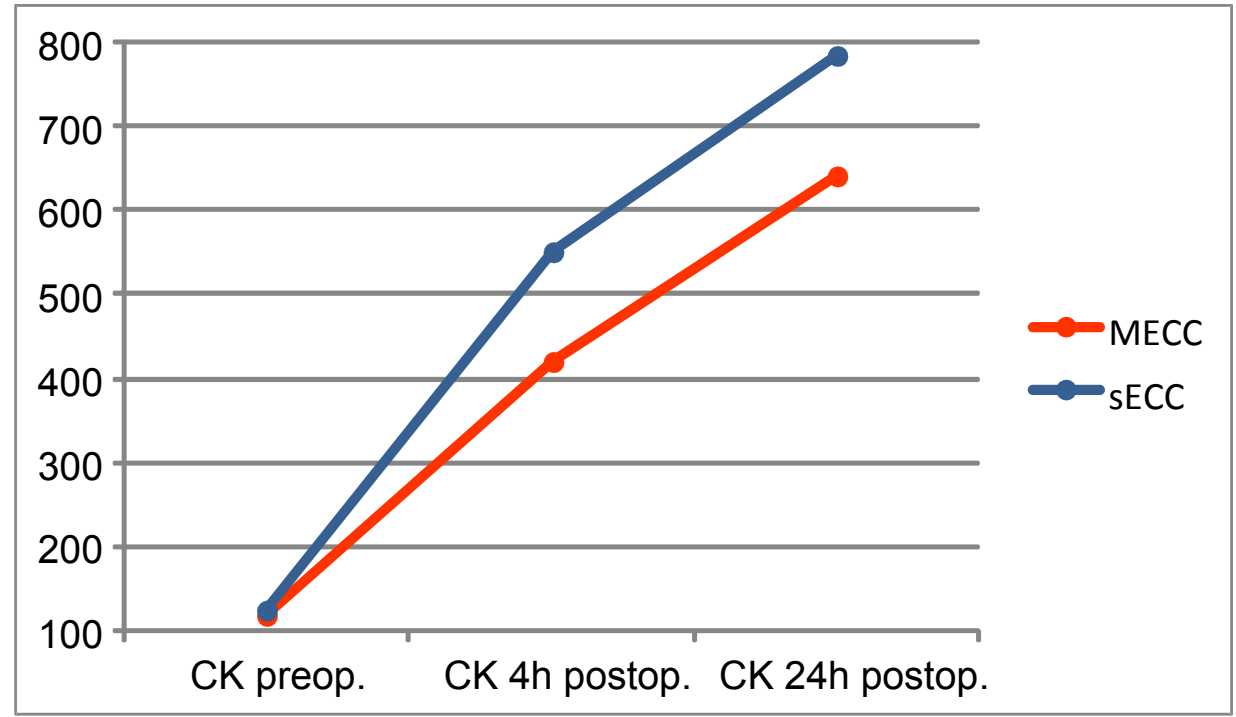

Fig. (3). Creatine kinase values.

CK-MB values of sECC group were $4 \mathrm{~h}$ postoperatively, as shown graphically in Fig. (5), higher than in the MECC group, however they reached not the significance (MECC: $35.0 \pm 33.5$ vs. sECC. $44.1 \pm 22.7 \mathrm{U} / 1 ; \mathrm{p}=0.052$ ).

$24 \mathrm{~h}$ postoperatively, the CK-MB values dropped in both groups again. The values in the MECC group decreased significantly here (MECC: $25.0 \pm 18.5$ vs. $\mathrm{sECC} 37.0 \pm 33.8 \mathrm{U} / \mathrm{l} \mathrm{p}=0.009$ ) (Fig. 4)

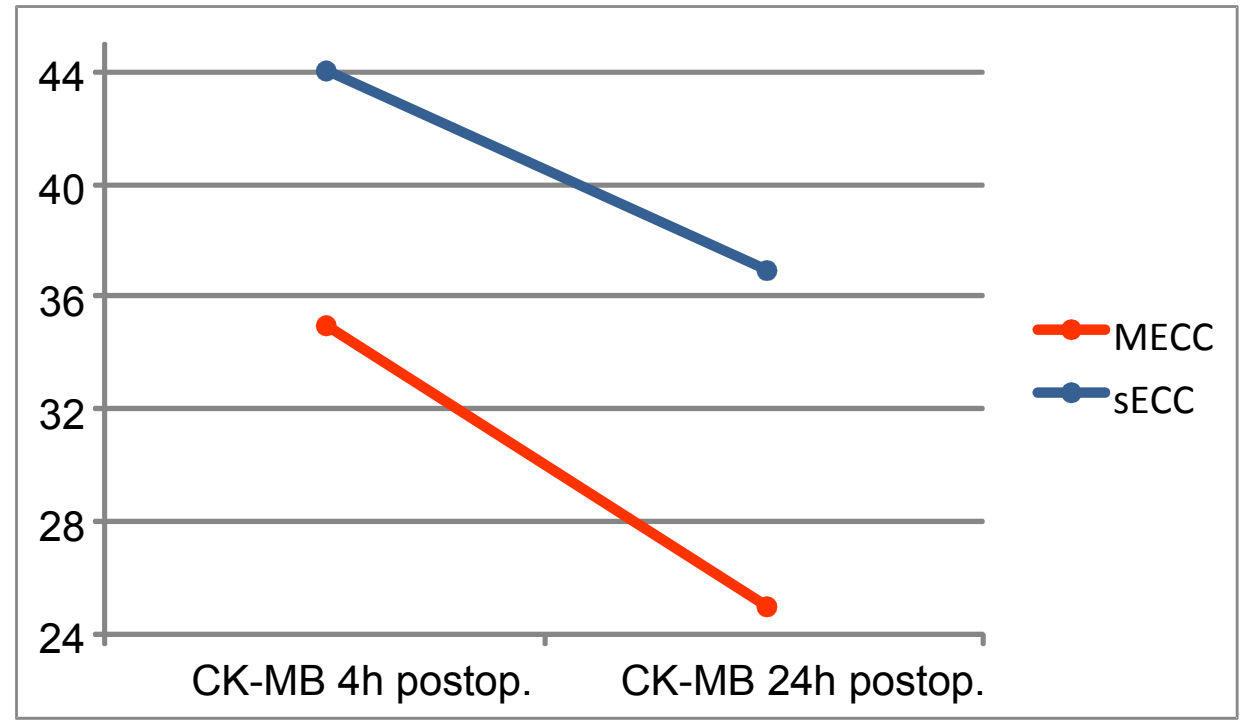

Fig. (4). CK-MB values.

\section{Postoperative Complications.}

The mortality rate was similar in both groups. One patient in the MECC group and one patient from the group sECC died of multiple organ failure. Both were operated on an emergency basis, and were preoperatively in decompensated cardiogenic shock The number of patients who required IABP was comparable in both groups. The incidence of newonset atrial fibrillation, wound complications, bronchopulmonary infections, acute renal failure, postoperative myocardial infarction, and transient ischemic attack were comparable in both groups.

No transitory psychotic syndrome was observed in the MECC group, this being observed in $17.8 \%$ of cases in the sECC group, $\mathrm{p}<0.001$. The incidence of re-thoracotomy for persistent bleeding and/or pericardial tamponade in the sECC group was significantly higher (Table 5). 
Table 5. Postoperative complications.

\begin{tabular}{|c|c|c|c|}
\hline & MECC & sECC & $\mathbf{p}$ \\
\hline Perioperative death, $\mathrm{n}(\%)$ & $1(1.2)$ & $1(1.4)$ & 1.000 \\
\hline IABP, n (\%) & $2(2.4)$ & $1(1.4)$ & 1.000 \\
\hline New onset AF, n (\%) & $11(13.3)$ & $7(9.6)$ & 0.475 \\
\hline Wound complications, n (\%) & $3(3.6)$ & $6(8.2)$ & 0.306 \\
\hline Bronchopulmonary infection, (\%) & $1(1.2)$ & $2(2.7)$ & 0.600 \\
\hline Transient psychotic syndrome, $\mathrm{n}(\%)$ & - & $13(17.8)$ & $<0.001$ \\
\hline CPR, n (\%) & $1(1.2)$ & - & 1.000 \\
\hline Re-thoracotomy, n (\%) & - & $4(5.5)$ & 0.046 \\
\hline Reintubation, $\mathrm{n}(\%)$ & - & $3(4.1)$ & 0.100 \\
\hline Acute renal failure, $\mathrm{n}(\%)$ & - & $2(2.7)$ & 0.217 \\
\hline Postoperative myocardial infarction, $\mathrm{n}(\%)$ & - & $1(1.4)$ & 0.468 \\
\hline TIA, n (\%) & - & $1(1.4)$ & 0.468 \\
\hline
\end{tabular}

IABP- intra-aortic balloon pump, AF-atrial fibrillation, CPR-cardiopulmonary reanimation TIA- transient ischemic attack

MECC - minimalized extracorporeal cardiopulmonary system

sECC - standard extracorporeal circulation

\section{DISCUSSION}

The use of extracorporeal circulation is associated with some already mentioned adverse effects $[4,5]$. The negative consequences are due both to physical damage of the various blood components passing through the extracorporeal circuit and to the immunologic response with its multiple consequences, secondary to the activation of different cellular and humoral cascades triggered by contact with foreign materials. The aim of our study was not to particularly investigate various pathomechanisms of the post ECC pathology but rather to report on the effects the MECC has on general outcome of the patients.

Besides using the minimalized circuit other adjuvant methods to reduce the priming volume were also incorporated in our strategy. This included a retrograde autologous priming by replacing part of the initial crystalloid solution from the tube circuit with the patient's own blood through the aortic cannula prior to starting CPB.

Our results demonstrate that the use of MECC system has a favorable influence on the peri-and post-operative transfusion usage. Compared with conventional CPB, the MECC system has also reduced the post-operative complications.

In our patients the incidence of perioperative transfusion in the sECC group lay around the 8.3-fold greater than that of the MECC group Also the amount of transfused RBCs was lower in the MECC group by nearly half (MECC: $375 \pm$ 141 vs. sECC $723 \pm 419 \mathrm{ml}, \mathrm{p}<0.001)$. FFP and Platelets had to be given only in the sECC group.

The most striking difference between the two groups was the dramatic reduction of blood product usage in the MECC technique. This difference persisted over the first 5 postoperative days, the progressive decline of the hematocrit values, often seen after conventional ECC being significantly milder.

This better blood conservation was already demonstrated by several previous studies [6 - 12].

The causes for these differences are multiple. The reduced hemodilution seems to be the most important factor contributing to the better postoperative hemostasis and lesser blood losses. It seems that targeted RBC, platelet or even individual coagulation factor replacement cannot substitute for the microenviroment present in the native blood. These results have been clearly demonstrated in the field of congenital cardiac surgery where for complex neonatal cases the priming with fresh full blood has yielded significantly better results than individual factor replenishment after the operation [13].

It is known that contact of blood with air has a significant effect on the hemolysis $[2,3]$ is completely eliminated. Nevertheless we observed a gradual decline of the RBC mass during the first postoperative days. This effect was weaker than in the conventional ECC group, but it signifies that the minimal circuit is not completely devoid of mechanical destructive actions. The other factor may reside in the cell saver constantly used for the MECC patients. Although the reinfused volume averaged $500 \mathrm{ml}$, the quality and lifespan of these washed erythrocytes is poor [3].

Time spent on ECC linearly increases the inflammatory reaction [14] so the shorter overall ECC time in the MECC 
group could also play a role. The ECC times were significantly shorter in the MECC group, yet the absolute values encountered in the conventional group lie within the acceptable limits so we speculate that the time factor has not played a role in the hematologic differences seen between the groups.

Another favorable effect on the blood management was observed in the differences between the chest drain losses in the first $24 \mathrm{~h}$. We are aware, that the volume output of the chest tube cannot be interpreted only as a marker of the postoperative hemostasis, the losses reflecting the overall perioperative fluid balance as well. The $>50 \%$ higher values observed in the conventional group clearly denote a favorable fluid balance in the MECC group with reduced third space redistribution too.

Due to the nearly complete heparin coating (excepting the aortic and venous cannulas) of the MECC circuit we targeted ACT values of 200 to $250 \mathrm{sec}$. Consequently the amount of administered heparin was lower. Although in both groups the antagonization was performed with 1:1 doses of protamine and the post-antagonization ACTs have not shown any significant differences between the groups, it is a well know phenomenon that residual heparin effect can frequently occur as a result of tissue washout, and the probability and magnitude of this is significantly higher in the almost 3 times higher amount of heparin required for the conventional circuit. This question was raised by other investigators with similar results $[15,16]$.

We also found significant differences regarding hospital stay $(12.0 \pm 4.1$ vs. $14.5 \pm 4.6$ days; $p<0.001)$, intensive care unit stay $(26.7 \pm 20.2$ vs. $54.5 \pm 68.9 \mathrm{~h} ; \mathrm{p}<0.001)$, intermediate care unit stay $(41.0 \pm 25.2$ vs. $57.3 \pm 46.4 \mathrm{~h}$; $\mathrm{p}=0.014)$ and intubation $(14.1 \pm 6.9$ vs. 36.4. $\pm 61.2 \mathrm{~h} ; \mathrm{p}<0.001)$. Ranucci et al., reported comparable results in a retrospective, nonrandomized analysis of more than 3,200 patients with reduction in intensive care unit stay, total hospital stay, and a general reduced morbidity [17].

In $17.8 \%$ of cases in the sECC group a transient psychotic syndrome occurred, but this was not observed in the MECC group $(\mathrm{p}<0.001)$. The need for a re-thoracotomy was significantly higher in the sECC $(0$ vs. 5.5\%, $\mathrm{p}=0.046)$; these results are similar to those of Koivisto et al. [18]. In addition, we found a slightly increased tendency to wound healing disorders, bronchopulmonary infections, acute renal failure, postoperative myocardial infarction and TIA in the sECC group, which however did not reach statistical significance. There were no differences between the two groups in mortality rate (MECC: $1.2 \%$ vs. sECC: $1.4 \%, \mathrm{p}=1.000$ ).

The number of patients who required IABP was similar in both groups (MECC: $2.4 \%$ vs. sECC: $1.4 \%, \mathrm{p}=1.000$ ).

Many studies indicated that the extent of the inflammatory response to extracorporeal circulation system has a negative influence on the clinical course [19]. It has also been observed, that blood transfusion constitutes a risk factor for an increased incidence of postoperative complications. Blood transfusions are associated with increased morbidity, prolonged ventilation, ICU and hospital length of stay [20 - 22].

In a further study of over 12,000 patients, who were followed over a period of 12 months after cardiac surgery, it was shown that the RBC and platelets transfusions have a negative long-term impact on the health of the patients [23]. Scott et al. [24] demonstrated a significantly prolonged ICU and total hospital length of stay in patients with allogeneic transfusions. The 30-day mortality, intubation, incidence of postoperative renal failure, neurological complications, bleeding and infections were also significantly increased.

There are larger studies of high-risk patients, showing that the MECC system significantly reduces the mortality rate [18]. One can certainly assume, that high-risk patients could have a most benefit from the MECC system. Other studies have reported an increased mortality rate in the conventional CPB group compared with the MECC group [12, 25]. We could not confirm these results due to low case numbers. Bianciri et al. [11] the results of prospective, randomized studies that compared the minimized ECC system with the sECC. They were able to show, that the use of minimized CPB were associated with a lower risk of postoperative blood loss, incidence of stroke and a slightly reduced mortality rate. However, there are many studies that could show no differences in intubation, intensive care and hospital stay duration $[26,27]$.

In the course of the operation in both groups a rise in CK level occurred. In sECC group CK rose to higher values and $4 \mathrm{~h}$ postoperatively, this level was significantly different. Also, the CKMB values $4 \mathrm{~h}$ postoperatively were higher in the sECC group, but did not reach statistical significance. In the MECC group, the levels dropped faster after $24 \mathrm{~h}$ postoperatively than in the sECC group (MECC $25.0 \pm 18.5$ vs. sECC $37.0 \pm 33.8 \mathrm{U} / \mathrm{l} ; \mathrm{p}=0.009$ ).

Generally similar results have been reached in comparable studies [12, 19, 25, 28]. The authors examined myocardial plasma markers during surgery and showed that there was reduced myocardial injury when using the MECC 
system. There are many speculations, why the MECC system achieves less myocardial injury than the conventional system.

\section{Study Limitations}

The results are limited by relatively small numbers of cases and the lack of randomization. The number of patients is too small to be illustrative in terms of mortality rate. Also, the MECC group were rather a low-risk patients, which becomes noticeable in the lower EuroScore. Possibly, the lower EuroScore in the MECC group could also influence the slightly positive results.

\section{CONCLUSION}

The MECC has the potential to reduce the quantity of transfusion and morbidity compared with conventional CPB. The main results of this study are the reduced need for transfusion and the better clinical course of the patients using the MECC system. During normothermic minimalized cardiopulmonary bypass autologous retrograde priming, intraoperative cell salvage, meticulous hemostasis and strict peri and postoperative volume management are crucial.

Regardless of whether the MECC can replace conventional CPB as the gold standard of cardiac surgery with CPB, it seems that minimalized ECC plays an important role in patients who would benefit from a reduced hemodilution and reduced systemic inflammation. Examples would be patients with anemia, thrombocytopenia, preoperative liver synthesis defect, existing organ dysfunction, and patients belonging to Jehovah's Witnesses.

\section{CONFLICT OF INTEREST}

All authors declare no financial disclosures. The paper is not under consideration elsewhere. None of the paper's contents have been previously published. All authors have read and approved the manuscript.

\section{ACKNOWLEDGEMENTS}

We appreciate the statistical help of M.A. Andreas Kögel, (Center for Data Analysis University Tuebingen).

\section{REFERENCES}

[1] van Straten AH, Bekker MW, Soliman Hamad MA, et al. Transfusion of red blood cells: the impact on short-term and long-term survival after coronary artery bypass grafting, a ten-year follow-up. Interact Cardiovasc Thorac Surg 2010; 10(1): 37-42. [http://dx.doi.org/10.1510/icvts.2009.214551] [PMID: 19815567]

[2] Bauer A, Diez C, Schubel J, et al. Evaluation of hemodynamic and regional tissue perfusion effects of minimized extracorporeal circulation (MECC). J Extra Corpor Technol 2010; 42(1): 30-9. [PMID: 20437789]

[3] Curtis N, Vohra HA, Ohri SK. Mini extracorporeal circuit cardiopulmonary bypass system: a review. Perfusion 2010; 25(3): 115-24. [http://dx.doi.org/10.1177/0267659110371705] [PMID: 20581025]

[4] Wippermann J, Albes JM, Hartrumpf M, et al. Comparison of minimally invasive closed circuit extracorporeal circulation with conventional cardiopulmonary bypass and with off-pump technique in CABG patients: selected parameters of coagulation and inflammatory system. Eur J Cardiothorac Surg 2005; 28(1): 127-32.

[http://dx.doi.org/10.1016/j.ejcts.2005.03.032] [PMID: 15939621]

[5] Vohra HA, Whistance R, Modi A, Ohri SK. The inflammatory response to miniaturised extracorporeal circulation: a review of the literature. Mediat Inflamm 2009; 2009: 707042. [http://dx.doi.org/10.1155/2009/707042]

[6] Dreizler T, Herbrechtsmeier T, Born F, et al. Auswirkungen von optimierten Bypass- Systemen mit retrogradem autologen Priming während der extrakorporalen Zirkulation bei Hochrisikopatienten. KARDIOTECHNIK 2010; 1/2010: 11-5.

[7] Wiesenack C, Liebold A, Philipp A, et al. Four years' experience with a miniaturized extracorporeal circulation system and its influence on clinical outcome. Artif Organs 2004; 28(12): 1082-8. [http://dx.doi.org/10.1111/j.1525-1594.2004.00030.x] [PMID: 15554936]

[8] Philipp A, Schmid F, Foltan M, et al. Miniaturisierte extrakorporale Kreislaufsysteme. Erfahrungsbericht aus über 1000 Anwendungen. Kardiotechnik 2006; 15(1): 3-8.

[9] Benedetto U, Angeloni E, Refice S, et al. Is minimized extracorporeal circulation effective to reduce the need for red blood cell transfusion in coronary artery bypass grafting? Meta-analysis of randomized controlled trials. J Thorac Cardiovasc Surg 2009; 138(6): 1450-3. [http://dx.doi.org/10.1016/j.jtcvs.2009.03.042] [PMID: 19660383]

[10] El-Essawi A, Hajek T, Skorpil J, et al. A prospective randomised multicentre clinical comparison of a minimised perfusion circuit versus conventional cardiopulmonary bypass. Eur J Cardiothorac Surg 2010; 38(1): 91-7. 
[http://dx.doi.org/10.1016/j.ejcts.2010.01.035] [PMID: 20206540]

[11] Biancari F, Rimpiläinen R. Meta-analysis of randomised trials comparing the effectiveness of miniaturised versus conventional cardiopulmonary bypass in adult cardiac surgery. Heart 2009; 95(12): 964-9.

[http://dx.doi.org/10.1136/hrt.2008.158709] [PMID: 19342377]

[12] Puehler T, Haneya A, Philipp A, et al. Minimized extracorporeal circulation system in coronary artery bypass surgery: a 10-year single-center experience with 2243 patients. Eur J Cardiothorac Surg 2011; 39(4): 459-64. [http://dx.doi.org/10.1016/j.ejcts.2010.08.006] [PMID: 20851618]

[13] Gruenwald CE, McCrindle BW, Crawford-Lean L, et al. Reconstituted fresh whole blood improves clinical outcomes compared with stored component blood therapy for neonates undergoing cardiopulmonary bypass for cardiac surgery: a randomized controlled trial. J Thorac Cardiovasc Surg 2008; 136(6): 1442-9.

[http://dx.doi.org/10.1016/j.jtcvs.2008.08.044] [PMID: 19114187]

[14] Kirklin JK, Westaby S, Blackstone EH, Kirklin JW, Chenoweth DE, Pacifico AD. Complement and the damaging effects of cardiopulmonary bypass. J Thorac Cardiovasc Surg 1983; 86(6): 845-57. [PMID: 6606084]

[15] Aldea GS, O'Gara P, Shapira OM, et al. Effect of anticoagulation protocol on outcome in patients undergoing CABG with heparin-bonded cardiopulmonary bypass circuits. Ann Thorac Surg 1998; 65(2): 425-33. [http://dx.doi.org/10.1016/S0003-4975(97)01347-7] [PMID: 9485240]

[16] Mahoney CB, Lemole GM. Transfusion after coronary artery bypass surgery: the impact of heparin-bonded circuits. Eur J Cardiothorac Surg 1999; 16(2): 206-10. [http://dx.doi.org/10.1016/S1010-7940(99)00157-8] [PMID: 10485422]

[17] Ranucci M, Isgrò G. Minimally invasive cardiopulmonary bypass: does it really change the outcome? Crit Care 2007; 11(2): R45. [http://dx.doi.org/10.1186/cc5777] [PMID: 17433112]

[18] Koivisto SP, Wistbacka JO, Rimpiläinen R, et al. Miniaturized versus conventional cardiopulmonary bypass in high-risk patients undergoing coronary artery bypass surgery. Perfusion 2010; 25(2): 65-70. [http://dx.doi.org/10.1177/0267659110364443] [PMID: 20179173]

[19] Remadi JP, Rakotoarivelo Z, Marticho P, Benamar A. Prospective randomized study comparing coronary artery bypass grafting with the new mini-extracorporeal circulation Jostra System or with a standard cardiopulmonary bypass. Am Heart J 2006; 151(1): 198. [http://dx.doi.org/10.1016/j.ahj.2005.03.067] [PMID: 16368318]

[20] Durandy YD. Pediatric cardiac surgery: effect of a miniaturized bypass circuit in reducing homologous blood transfusion. J Thorac Cardiovasc Surg 2009; 138(6): 1454.

[http://dx.doi.org/10.1016/j.jtcvs.2009.06.030] [PMID: 19931674]

[21] Murphy GJ, Angelini GD. Indications for blood transfusion in cardiac surgery. Ann Thorac Surg 2006; 82(6): 2323-34. [http://dx.doi.org/10.1016/j.athoracsur.2006.06.020] [PMID: 17126171]

[22] Koch CG, Li L, Duncan AI, et al. Morbidity and mortality risk associated with red blood cell and blood-component transfusion in isolated coronary artery bypass grafting. Crit Care Med 2006; 34(6): 1608-16. [http://dx.doi.org/10.1097/01.CCM.0000217920.48559.D8] [PMID: 16607235]

[23] Koch CG, Khandwala F, Li L, Estafanous FG, Loop FD, Blackstone EH. Persistent effect of red cell transfusion on health-related quality of life after cardiac surgery. Ann Thorac Surg 2006; 82(1): 13-20. [http://dx.doi.org/10.1016/j.athoracsur.2005.07.075] [PMID: 16798179]

[24] Scott BH, Seifert FC, Grimson R. Blood transfusion is associated with increased resource utilisation, morbidity and mortality in cardiac surgery. Ann Card Anaesth 2008; 11(1): 15-9.

[http://dx.doi.org/10.4103/0971-9784.38444] [PMID: 18182754]

[25] Puehler T, Haneya A, Philipp A, et al. Minimal extracorporeal circulation: an alternative for on-pump and off-pump coronary revascularization. Ann Thorac Surg 2009; 87(3): 766-72. [http://dx.doi.org/10.1016/j.athoracsur.2008.11.050] [PMID: 19231386]

[26] Wiesenack C, Liebold A, Philipp A, et al. Four years' experience with a miniaturized extracorporeal circulation system and its influence on clinical outcome. Artif Organs 2004; 28(12): 1082-8.

[http://dx.doi.org/10.1111/j.1525-1594.2004.00030.x] [PMID: 15554936]

[27] Abdel-Rahman U, Ozaslan F, Risteski PS, et al. Initial experience with a minimized extracorporeal bypass system: is there a clinical benefit? Ann Thorac Surg 2005; 80(1): 238-43.

[http://dx.doi.org/10.1016/j.athoracsur.2005.02.032] [PMID: 15975373]

[28] Minimal versus conventional cardiopulmonary bypass: assessment of intraoperative myocardial damage in coronary bypass surgery. Eur J Cardiothorac 2005; 28: 701-4.

(C) Lisy et al.; Licensee Bentham Open.

This is an open access article licensed under the terms of the Creative Commons Attribution-Non-Commercial 4.0 International Public License (CC BY-NC 4.0) (https://creativecommons.org/licenses/by-nc/4.0/legalcode), which permits unrestricted, non-commercial use, distribution and reproduction in any medium, provided the work is properly cited. 